\title{
EDUCAÇÃO NO TRÂNSITO: MINIMIZANDO O CONFLITO ENTRE A CIDADE E O CIDADÃO
}

\author{
LYRIO FILHO, A. Arquiteto, MSc. ESDI/ UERJ arnaldo.lyrio@gmail.com \\ MEDEIROS, L. Prof. DSc. ESDI/ UERJ ligiamsmedeiros@gmail.com
}

\section{Resumo}

A implantação de empreendimentos imobiliários de grande porte nas cidades é fator de desenvolvimento socioeconômico para a região em que se localizam. Justamente por serem de grande porte, causam transformações significativas não apenas na paisagem, como na dinâmica do local. Por isso, são necessárias adaptações na infraestrutura, notadamente no sistema viário, em consequência do incremento de viagens de pessoas e movimentações de cargas. Essas mudanças no trânsito produzem conflitos potenciais entre modos de viagem motorizados (carros, ônibus, caminhões) e não-motorizados (pessoas a pé, de bicicleta). As campanhas de educação no trânsito (CE's) para Polos Geradores de Viagens (PGV's), implementadas pela Companhia de Engenharia de Tráfego do Rio de Janeiro - CET Rio visam minimizar esses conflitos. O presente artigo tem como objetivo descrever a sequência de etapas na implantação de uma campanha de educação de trânsito a partir de um exemplo de empreendimento no Rio de Janeiro. Observou-se que o desenvolvimento de CE's é tarefa complexa e interdisciplinar. O que está sendo ali transmitido não é meramente informativo, mas tem forte relevância para a segurança e integridade dos cidadãos. Em vista disso, precisa ser levada a termo de modo que a informação atinja o destinatário de forma íntegra, clara, sem ambiguidades. O exemplo analisado mostra que existe um campo fértil de estudos interdisciplinares para o desenvolvimento de elementos de educação de trânsito mais eficazes.

Palavras-chave: Educação para o trânsito, Empreendimentos imobiliários de grande porte, Ergonomia do ambiente construído, Polos Geradores de Viagens.

\begin{abstract}
The implementation of large real estate projects in the cities is socio-economic development factor for the region where they are located. Just by being large, they cause significant changes not only in the landscape, but also in the dynamics of the site. Therefore, adjustments are needed in local infrastructure, particularly in the road system as a result of increased travel of people and cargo movements. These changes in traffic produce potential conflicts between motorized travel modes (cars, buses, trucks) and non-motorized (people walking, cycling). The education campaigns in traffic (CE's) for Trip Generating Poles (PGV's), implemented by the City Hall Traffic Engineering Company - CET Rio aim to minimize these conflicts. This paper intends to describe the sequence of steps in the implementation of a traffic education campaigns from a case study in Rio de Janeiro. It was observed that the development of such a campaign is complex and interdisciplinary task. What is being transmitted there is not merely informative, but has strong relevance to the security and integrity of citizens. As a result, it needs to be brought to completion so that the information reaches the addressee full, clear and unambiguous. The analyzed sample shows that there is a fertile field for interdisciplinary studies for developing more efficient traffic education elements.
\end{abstract}

Keywords: Education for the traffic, Real state projects large size, Built environment ergonomics, Trip Genereting Poles

\section{Introdução}

Templos, arenas, praças, mercados, teatros, estádios eram as edificações típicas das cidadesestados da Grécia antiga. Por essas construções circulavam os cidadãos gregos, a pé ou, em menor número, em alguma montaria ou conduzindo um veículo de tração animal. As cidades 
da época eram percorridas dessa forma e somente milhares de anos mais tardes os automóveis iriam tomar uma parcela relevante do espaço público. Os aglomerados urbanos evoluíram e as antigas urbes deram lugar a metrópoles, graças às distâncias, agora vencidas por veículos automotores. A invenção do automóvel trouxe mais autonomia e mobilidade aos seus condutores que podiam se deslocar, então, para todo e qualquer lugar que o veículo pudesse chegar. Ruas, avenidas e estradas passaram a ocupar uma área considerável do tecido urbano e a indústria automobilística se tornou símbolo de desenvolvimento de uma nação. Assim, os automóveis se tornaram acessíveis para grande parte da população urbana e a infraestrutura viária exige atualmente atenção especial na gestão das cidades. Como consequência, a segurança e a fluidez do trânsito são sensíveis às variações no número e intensidade dos deslocamentos no sistema viário e qualquer mudança, transformação ou construção pode influenciá-las significativamente. Os usuários do espaço público urbano, tanto motoristas quanto pedestres ou ciclistas, tanto crianças quanto jovens e idosos, com ou sem restrição de mobilidade física, se deparam diariamente com alterações no seu trajeto decorrentes de obras públicas ou privadas que modificam seus percursos total ou parcialmente. Diariamente, essas pessoas são expostas a conflitos com elementos do sistema viário, urbanísticos e arquitetônicos sem a mínima informação sobre a sua ocorrência.

Este trabalho tem como objetivo contribuir com a modelagem de CE's, considerando a ausência de registros de iniciativas semelhantes voltadas especificamente para PGV's. A metodologia utilizada foi o estudo de caso, baseado em experiência obtida na criação e implementação de campanhas de educação para o trânsito ao longo dos últimos oito anos, sendo a campanha apresentada o resultado do conhecimento acumulado nesse período.

\section{Estrutura do trabalho}

O desenvolvimento e a formatação de CE's têm como diretriz determinante o fato de se tratarem de ferramentas de Engenharia de Tráfego, pois segundo esta disciplina, a Educação é um dos fatores considerados na implementação de projetos de tráfego. A Engenharia de Tráfego preconiza que programas de trânsito precisam da concorrência de três ações para garantir sua segurança, fluidez e conforto. Nos Estados Unidos essas ações são conhecidas como o conjunto 3 E's, quais sejam, Engineering, Education e Enforcement (Rozestraten, 1988), traduzidas para o português como Engenharia, Educação e Esforço Legal. Embora os E's de Engenharia e de Esforço Legal, ou fiscalização, sejam identificados frequentemente em ações de engenharia de tráfego, a Educação é aplicada timidamente; o presente trabalho explora essa lacuna e se estrutura em três partes:

1- Campanhas de educação para o trânsito (CE) em PGV's: restrições e obstáculos. Neste item se contextualiza o problema da pesquisa, com um breve relato sobre a análise de impacto viário e da influência dos PGV's sobre os hábitos de mobilidade dos usuários do sistema viário do seu entorno.

2- Estudo de caso. A descrição de caso visa tecer um cenário do estágio atual da modelagem de CE's e da metodologia para a sua construção, de modo a tornar visíveis os espaços em que a inserção de princípios de Design e Ergonomia são necessários, conforme o item 3.

3- Diretrizes ergonômicas e projetuais propostas para CE's. Nesta parte se pontuam os aspectos relevantes que foram observados a partir da descrição do estudo de caso.

Nas Conclusões se apresentam recomendações a serem observadas na modelagem de CE's.

\section{1- Campanhas de educação para o trânsito em PGV's: restrições e obstáculos}

Nos dias de hoje a implantação de grandes empreendimentos como estádios, shopping centers e casas de espetáculos, por exemplo, implicam em transformações importantes no espaço urbano. Kneib et al (2012 - p. 673) explicam esse fato da seguinte forma:

As cidades constituem elementos dinâmicos, sujeitos a alterações constantes e desafiadoras para apropria vida urbana. Toda aglomeração urbana é conformada por 
elementos que se relacionam, de forma sistêmica, onde o impacto em um destes, inevitavelmente, acaba afetando os demais, em escalas mais ou menos perceptíveis.

Para Portugal (2012) as metrópoles latino-americanas se caracterizam pela desordem e a desigualdade em termos de ocupação e uso do solo urbano, o que agrava a desintegração dos sistemas de transportes. Segundo este autor, no processo de interação entre transporte e uso do solo se destacam os empreendimentos de grande porte, denominados como Polos Geradores de Viagens (PGV's). Trata-se de edificações de naturezas diversas cuja característica comum é o desenvolvimento de atividades que atraem uma quantidade expressiva de pessoas, "produzindo um contingente significativo de viagens, [necessitando, assim] de grandes espaços para estacionamento, carga e descarga e embarque e desembarque, promovendo, consequentemente, potenciais impactos" (PORTUGAL, 2012, p. VIII).

As campanhas de educação para o trânsito tratadas no presente artigo diferem em objetivo e prazo das campanhas educativas veiculadas na mídia sobre o uso do cinto de segurança e a Lei Seca. Se estas procuram influenciar no comportamento do conjunto geral de motoristas, o tempo de campanha é longo, a mensagem é repetitiva e o âmbito de aplicação é amplo. No caso das CE's aqui abordadas, o campo de atuação se restringe à área de influência dos PGV's e as mensagens devem durar o tempo igual ao da construção dos empreendimentos, prolongando-se por no máximo três meses após a sua inauguração. As peças de comunicação são aplicadas, por conseguinte, de modo a influenciar estritamente no comportamento do público que circula nessa região, ou que passará a utilizá-la.

Em vista das peculiaridades de cada empreendimento projetado, bem como das características específicas de localização e de configuração da infraestrutura viária da região onde este será implantado, os procedimentos para implantação de CE's podem diferir bastante no que diz respeito ao detalhamento da campanha. Entretanto as diretrizes que orientam a lógica projetual aplicável seguem, em linhas gerais, a metodologia descrita no estudo de caso relatado no item 3. Cabe destacar as restrições e obstáculos que se pode observar ao longo do processo de decisão sobre CE's. A primeiras delas surge bem no início do processo de análise de impacto viário e tem como causa a inexperiência dos empreendedores com iniciativas desse tipo. Ocorre que a análise de impacto viário é um dos passos do processo de aprovação de projetos e o atendimento a exigências dos órgãos públicos tem um caráter burocrático, com tendência a achar a formatação de CE's acessória. Convém lembrar, todavia, que CE's, longe de serem supérfluas, se agregam à estrutura tríplice de variáveis preconizada pela Engenharia de Tráfego (Engenharia, Esforço legal e Educação). Outra restrição, que decorre dessas primeiras dificuldades, é que os empresários da construção civil, familiarizados com o universo criativo e interdisciplinar da comunicação para fins de divulgação e venda das unidades do empreendimento, não costumam associar os benefícios de uma boa campanha de comunicação ao objetivo de se promover segurança aos usuários daquele local.

Por fim, o acompanhamento das CE's continua após a concessão do Habite-se, sendo essa a fase importante da campanha, em vista da nova movimentação de veículos após a inauguração do empreendimento. Vale, nesse sentido, um esforço de regulamentação de CE's, tanto em termos institucionais como em termos metodológicos.

\section{2- Estudo de Caso}

\section{1- Breve histórico}

Em 2006 foi autuado um processo administrativo na CET Rio para análise do impacto viário de um empreendimento, composto de dois blocos residenciais e um hotel, situado na Avenida Lúcio Costa, na orla da praia da Barra da Tijuca, no ponto em que o logradouro reduz a sua largura de seis faixas em duas pistas para três faixas em uma pista apenas (Figuras 1 e 2). $\mathrm{O}$ impacto do programa sobre o sistema viário local é evidente, se observado o seu porte e a configuração do logradouro naquele ponto. A solução para minimizar esse impacto foi a 
criação de um acesso ao empreendimento por uma pista suplementar que, além dos acessos, permite a saída dos veículos tanto em direção ao Recreio dos Bandeirantes quanto o retorno na direção Recreio-Barra da Tijuca. Todos os movimentos veiculares foram remanejados de modo que a fluidez do tráfego fosse preservada ao máximo. As adaptações realizadas influenciam significativamente, no entanto, os hábitos dos usuários que frequentam aquela região e serão motivo de cuidado e atenção dos novos usuários do empreendimento. $O$ foco da $\mathrm{CE}$, então, foi a conscientização, tanto dos novos usuários quanto dos usuários habituais daquela região, de que o sistema viário sofreria adaptações importantes e que eles deveriam trafegar com cuidado, atender não apenas às indicações da sinalização vertical e horizontal regulamentares, mas também a sinalização temporária complementar, sobre travessias, entrada e saída de veículos e as adaptações na geometria da via no trecho considerado. Importante lembrar que, bem antes da inauguração do empreendimento, a campanha de educação no trânsito deve ter como público-alvo inicial a população de obra, que lida com a movimentação de materiais e pessoas que visitam diariamente o canteiro de obras. Por isso existe a recomendação de que a movimentação de veículos deve ser sempre informada à regional da CET Rio com antecedência para que se procedam as devidas operações no tráfego local.

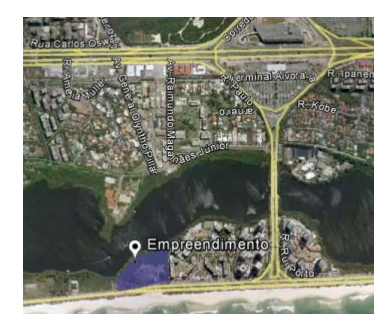

Figura 1: Localização geral do empreendimento.

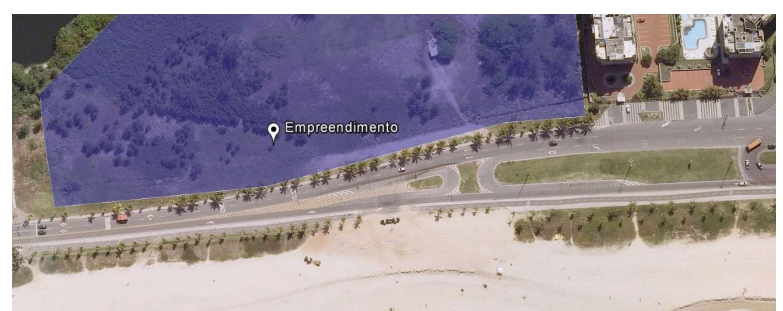

Figura 2: Acesso em 2006. Fonte: Google Earth

\subsection{Metodologia adotada}

O planejamento da campanha de educação no trânsito (CE) foi realizado nas seguintes etapas.

\subsubsection{Início do planejamento}

O planejamento tem início após a aprovação dos seguintes projetos junto à CET Rio:

- Projetos apresentados pelo Arquiteto, orientado pela Consultora de Tráfego:

- Projeto dos acessos de automóveis, pedestres, carga e ônibus ao empreendimento, com indicação de rebaixos de meio-fio, calçada e ciclovia, onde houver.

- Projetos apresentados pela Consultora de tráfego:

- Projeto geométrico do logradouro;

- Projeto de sinalização de tráfego, vertical, horizontal e semafórica.

2.2.2 Lançamento dos projetos aprovados em uma planta-base

Permite a análise da movimentação dos modos de viagens motorizados e não-motorizados.

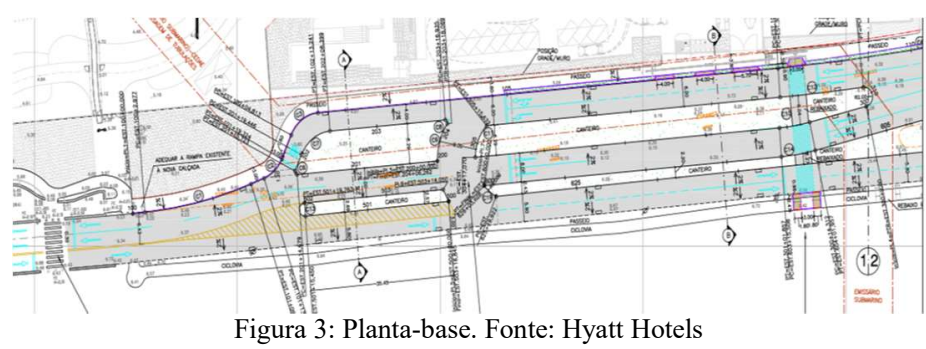

\subsubsection{Mapeamento dos conflitos}

Identificam-se os conflitos potenciais entre veículos e pessoas observados na planta-base. Eles são classificados e transcritos em plantas específicas de mapeamento dos conflitos (Figuras 4 e 5) 


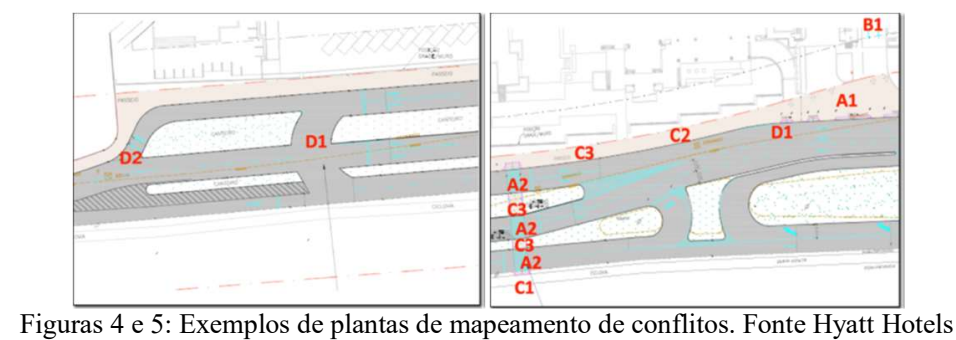

Eis alguns exemplos de conflitos identificados e os locais onde ocorrem:

a) Veículo X Pedestre e Ciclista

A1---portões de acesso de veículos do Hotel (caminhão, ônibus) e dos Apartamentos

A2---travessia semaforizadas da Av. Lúcio Costa

b) Veículo X Ciclista

B--- interior do empreendimento, nas rampas de descida ao subsolo

c) Ciclista X Pedestre

C1--- Ciclovia

C2--- Travessias semaforizadas

C3--- Calçada em frente ao Hotel

d) Veiculo X Veículo

D1--- Novo retorno veicular

D2--- Nova pista lateral junto ao empreendimento

2.2.4 Definição de mensagens de comunicação, de acordo com o tipo de conflito e o públicoalvo considerado.

Seguem alguns exemplos de mensagens de comunicação, de acordo com o público-alvo.

a) PARA O MOTORISTA

A1. O pedestre sempre tem prioridade sobre o veículo.

A1. Ao entrar no Hyatt, atenção! Pare ao avistar algum pedestre atravessando (Placa A32b).

B1. Circulando pelo estacionamento, mantenha a velocidade reduzida (Placa R19-20km).

B1. Ao sair do estacionamento, dê preferência ao pedestre (Placa A32a) e observe se há ciclistas (Placa A30b)

D2. Na saída do Hyatt, pare (Placa R1) e aguarde o momento mais seguro para chegar na Av. Lúcio Costa.

D1. Para retornar, siga pela pista lateral.

b) PARA O PEDESTRE

A1. É mais seguro e confortável atravessar na faixa de pedestre. Observe as rampas acessíveis.

A1. Atravesse no lugar certo.

A2. Para sua segurança, acione a botoeira.

c) PARA O CICLISTA

C3. Na calçada, a preferência é sempre do pedestre. Proteja---o.

C1. Saindo da ciclovia, desça da bicicleta.

C2. Estacione em uma das vagas disponíveis no subsolo.

B1. Cuidado com as saídas de veículo do estacionamento. Pare e aguarde o melhor momento.

A definição dessas mensagens parte de enunciados que descrevem circunstâncias desejadas em termos de redução de impactos decorrentes de conflitos entre os diferentes modos de viagem, como demonstra o exemplo utilizado na $\mathrm{CE}$ estudada.

MOTORISTA

Circulando com segurança e

Protegendo o Pedestre e o Ciclista

PEDESTRE

Atravessando no lugar certo

CICLISTA

Circulando e protegendo o pedestre

Desses enunciados se definem as mensagens que serão comunicadas nos pontos de conflitos apontados na planta-base. Os tipos de materiais, suportes e design gráfico se desenvolvem de acordo com os locais onde essas mensagens serão afixadas, considerando o ponto de vista do público receptor. São cartazes, adesivos, banners, flyers, web site. No caso do complexo 
residencial e hoteleiro, as mensagens são bilíngues (português - inglês), atendendo à presença de turistas, hóspedes ou não, que vão circular na região do empreendimento.

\subsubsection{Definição da linguagem gráfica}

A linguagem gráfica está associada à tipologia, à localização e ao impacto viário considerado para o do empreendimento que, consideradas essas variáveis, deve ter um projeto gráfico de alta qualidade. A Figura 6 permite comparar a formatação proposta no início do planejamento da CE e a forma adotada.

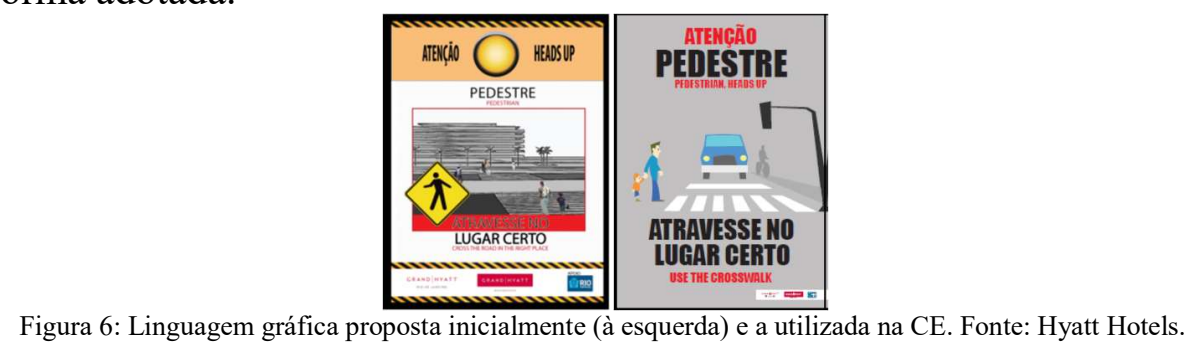

A partir da exposição do presente caso apresentam-se a seguir propostas para aplicação de princípios de Design e Ergonomia em CE's.

\section{3- Diretrizes ergonômicas e projetuais propostas para CE's}

As propostas relacionadas neste item pontuam aspectos que devem ser observados na construção de CE's, com a inserção de princípios do Design e da Ergonomia.

\section{1- Tempo}

O curto espaço de tempo para se planejar e implementar uma CE é um elemento complicador. Com efeito, o plano da CE é apresentado em geral nos últimos meses de obra e deve ser submetido ao órgão de trânsito, que o analisa e sugere ajustes ao trabalho. Um cronograma é essencial para ordenar as etapas e os prazos do desenvolvimento (D'Agostini; Gomes, 2010 p. 26). A sugestão, para o planejamento de CE's é, portanto, a elaboração de cronogramas cujo inicio se situe o mais próximo possível do início das obras, pois existem tarefas que podem ser executadas independentemente dos projetos finais do arquiteto e do consultor de tráfego.

3.2- Comunicação e Linguagem gráfica

A geração de mensagens, na metodologia da CE apresentada, possui encadeamento adequado, pois se baseia em enunciados que descrevem situações desejáveis de segurança para o pedestre. O resultado final, porém, pode se afastar do óbvio com a aplicação, por exemplo, de técnicas de brainstorming que explorem as peculiaridades de cada caso.

Em se tratando de projetos em que o ambiente urbano é o pano de fundo, a linguagem gráfica a ser adotada deve observar as características citadas por Hunt (2003) em D’Agostini; Gomes (2010, pag. 29), quais sejam:

1. São tangíveis, existem no espaço, estão ao alcance das mãos, possuem profundidade;

2. Possuem uma escala em relação ao homem e a arquitetura do local;

3. Estão sempre fazendo parte de um contexto, ou seja, existe um cenário à sua volta;

4. São complexos, exigindo o conhecimento de materiais e técnicas de fabricação;

5. São percebidos ou observados muitas vezes quando se está em movimento;

6. Precisam ser resistentes e duráveis;

7. Sofrem a ação do tempo, como: o sol, a chuva, maresia, a umidade;

8. São muitas vezes projetados em conjunto com arquitetos e engenheiros;

9. Exigem um tempo de desenvolvimento maior;

10. São parte de algo, como: uma cidade, um parque, um aeroporto.

Cabe destacar que as placas de educação de trânsito não podem ser confundidas com anúncios publicitários nem com informações menos relevantes. Elas precisam ter uma linguagem própria, distinta, reconhecível, para se tornarem efetivas.

\section{3- Ergonomia}


O trabalho desenvolvido considerou, no seu planejamento e elaboração, o ponto de vista de cada receptor das mensagens. Existe espaço, entretanto, para aperfeiçoamentos se observarmos aspectos ligados à ergonomia, de maneira mais detalhada.

O planejamento de CE's deve, portanto, contemplar as interações entre o espaço onde ela será implantada e a circulação do público. Pessoas com deficiências ou com mobilidade reduzida são mais vulneráveis em situações de conflito e merecem cuidados especiais. Panero e Zelnik (2013) descrevem circunstâncias e medidas que devem ser levadas em conta. Segundo estes autores, "deve-se ter cuidado ao aceitar padrões dominantes ou regras de "olhômetro" para estabelecer espaços livres sem questionar sua validade antropométrica, mesmo que esses padrões possam estar em códigos ou regulamentações existentes". (PANERO; ZELNIK, 2013 p.264)

\section{Conclusões}

Este artigo demonstrou que existe um campo fértil para estudos interdisciplinares de desenvolvimento de elementos de educação de trânsito mais eficazes e que a modelagem de uma CE em PGV's é tarefa complexa e interdisciplinar, com reflexos importantes para a segurança e integridade dos cidadãos. Consequentemente, precisa ser levada a termo de modo que a informação atinja o destinatário de forma íntegra, clara, sem ambiguidades.

Os resultados práticos da aplicação da CE são difíceis de serem tabulados, em vista do seu caráter qualitativo. No entanto é recomendável que se criem indicadores de desempenho de permitindo aperfeiçoamentos e ampliando assim seus benefícios.

Constata-se, ainda, a importância de se desenvolverem conjuntos de gabaritos e parâmetros para casos gerais, bem como algumas recomendações para usos específicos, de acordo com a tipologia, a localização e o público-alvo, gerando, assim um quadro de boas práticas para CE's e facilitando o trabalho de modelagem. Essas iniciativas favorecem, também, a compreensão dos empreendedores sobre a importância da inserção de CE's em seus projetos pois demonstram sua preocupação com a segurança e o bem-estar da população.

\section{Agradecimentos}

A metodologia para desenvolvimento de CE's, descrita neste trabalho, recebeu contribuições importantes de profissionais que, em suas especialidades, transformaram os conceitos debatidos nas diversas reuniões de trabalho em realidade. Esses profissionais são: Ricardo Basílio Mestre em Tecnologia Educacional, Administrador, Analista de Sistemas, Designer que coordenou o projeto (desenvolvimento) e o ilustrou; Miriam Soares, Engenheira Civil, Mestre em Ciências em Engenharia de Transportes, responsável pelo Estudo de Tráfego para o empreendimento e Consultora em Engenharia de Tráfego para a CE; Bruna Bernini Barbieri, Arquiteta e Urbanista, com MBA em Edifícios Sustentáveis, representante do empreendedor, que implantou a campanha, com o apoio e anuência da empresa Hyatt Hotels, e que autorizou a transcrição do material da sua Campanha de Educação no Trânsito neste artigo; Sheila Castro, Arquiteta da CET Rio, Mestre em Engenharia de Transportes, que validou a campanha e acompanhou a sua implementação junto ao empreendedor.

\section{Referências Bibliográficas}

HUNT, W. Environmental Graphics: Projects \& Process. New York: Harper Collins, 2003.

KNEIB, E. C.; TEDESCO G. M. I.; BARROS A. P. B. G.; Paiva M. PGVs e Centralidades: impactos na escala urbana e metropolitana. In: Licínio da Silva Portugal. (Org.). Polos Geradores de Viagens Orientados à qualidade de vida e ambiental. $1^{\text {a }}$ ed. Rio de Janeiro: Interciência, p. 671-704.

PANERO, J.; ZELNIK, M. Dimensionamento humano para espaços públicos. Barcelona: Editorial Gustavo Gilli, 2013

PORTUGAL, L. (org.). Polos geradores de viagens orientados à qualidade de vida e ambiental: modelos e taxas de geração de viagens. Rio de Janeiro: Interciência, 2012.

ROZESTRATEN, R. J. A. Psicologia do trânsito: conceitos e processos básicos. São Paulo: EPU/EDUSP, 1988. 